\title{
Seroprevalence and risk factors of Mycoplasma capricolum subsp. capricolum among small ruminants in northern Jordan
}

\author{
Waleed Al-Momani ${ }^{a}$, Robin R.A.J. Nicholas ${ }^{b}$ and Mahmoud N. Abo-Shehadac \\ a Department of Basic Medical Sciences, Faculty of Medicine, Yarmouk University, Jordan \\ b Mycoplasma Group, Department of Bacterial Diseases, Veterinary Laboratories Agency- \\ Weybridge, New Haw, Addlestone, United Kingdom \\ c Parasitology Research Laboratory, London School of Hygiene and Tropical Medicine
}

$\begin{array}{lll}\text { Received: } 10 / 6 / 2021 & \text { Revised: 20/6/2021 Accepted: 30/6/2021 }\end{array}$

DOI: https://doi.org/10.31559/CRMI2021.2.1.3 


\title{
Seroprevalence and risk factors of Mycoplasma capricolum subsp. capricolum among small ruminants in northern Jordan
}

\section{Waleed Al-Momani*a, Robin R.A.J. Nicholas ${ }^{b}$ and Mahmoud N. Abo-Shehadac}

a Department of Basic Medical Sciences, Faculty of Medicine, Yarmouk University, Jordan

b Mycoplasma Group, Department of Bacterial Diseases, Veterinary Laboratories Agency-Weybridge, New Haw, Addlestone, United Kingdom

c Parasitology Research Laboratory, London School of Hygiene and Tropical Medicine

Received: 10/6/2021 Revised: 20/6/2021 Accepted: 30/6/2021 DOI: https://doi.org/10.31559/CRMI2021.2.1.3

\begin{abstract}
:
During 2002-2003 the seroprevalence of Mycoplasma capricolum subsp. capricolum was studied among 104 small ruminant's flocks (18 sheep, 27 goat and 59 mixed flocks) in northern Jordan. At least 5 serum samples/flock were tested using iELISA test. The true flock-level seroprevalences of Mycoplasma capricolum subsp. capricolum were 56\%,39\%, 28\% in small ruminant (sheep and goats), sheep and goats respectively. There was no significant difference $\left(X^{2}=2\right.$, d.f. $\left.=1, p=0.15\right)$ between seroprevalences in sheep and goats at the flock level. A total of 29 variables including production and health management practices were tested as risk factors for seropositive flocks and analyzed using logistic regression analysis. The use of communal grazing was found to be a risk factor for Mycoplasma capricolum subsp. capricolum seropositivity with odds ratio of 5.2 and drinking the animals with spring water was a protective factor with odds ratio of 0.27 . More than

half of the examined flocks were seropositive to Mycoplasma capricolum subsp. capricolum indicating a role for Mycoplasma capricolum subsp. capricolum in contagious agalactiae in small ruminants. The education of farmers regarding the use of communal grazing and housing the newborn in separate barns is expected to help reducing the Mycoplasma capricolum subsp. capricolum infections in their flocks.
\end{abstract}

Keywords: Mycoplasma capricolum subsp; capricolum; small ruminants; sheep; goat; seroprevalence; risk factors; Jordan.

\footnotetext{
* Corresponding Author

Waleed Al-Momani

Department of Basic Medical Sciences, Faculty of Medicine, Yarmouk University, Jordan

E-mail: waleed.momani@yu.edu.jo
} 


\section{Introduction}

Mycoplasma capricolum subsp. capricolum $(M c c)$ is one of four mycoplasmas designated by OIE as a cause of contagious agalactia (CA) (a list B disease). Similar clinical and pathological findings also caused by Mycoplasma spp. that are grouped in the "Mycoides cluster", namely, Mycoplasma mycoides subsp. capri, Mycoplasma putrfaciens and Mycoplasma agalactiae (Nicolet, 1994). Although mycoplasmas are host specific, closely related animal species may share the same Mycoplasma spp. including sheep and goats (Ruffin, 2001). $M$. capricolum subsp. capricolum is primarily a pathogen of goats and may cause acute disease and death (DaMassa et al., 1992).

Natural infection leads to contagious agalactia syndrome, characterized by mastitis, arthritis and keratoconjunctivitis (Bolske, 1995). Experimental infection results in an acute syndrome of septicemia and severe arthritis. Although, $M$. capricolum subsp. capricolum is seldom isolated from pneumonic lesions (Bolske, 1995), kids do show acute respiratory distress in experimental infections (Rodriguez et al., 1998) and pneumonia may be seen at necropsy. Severe joint lesions are seen in experimental infections and accompanied by intense periarticular subcutaneous edema affecting tissues to some distance from the joint (Bolske et al., 1988). Fatal septicemic polyarthritis may occur in kids or lambs fed with contaminated milk with $M c c$ mastitis. Sporadic arthritis and abscesses may be less serious manifestations of $M$. capricolum subsp. capricolum (Perreau and Breard, 1979).

The diagnosis of $M$. capricolum subsp. capricolum is based on clinical signs, isolation and identification of the causal agent and other laboratory techniques including serological tests (Poveda and Nicholas, 1998) and molecular biology techniques (Bashiruddin et al., 1994).

The re-infection of the same herd is a major problem of sheep and goat mycoplasmoses. The main source of re-infection is the chronic carriers of mycoplasma from inside the herd and/or newly introduced animals to the herd. Some strains of mycoplasma can persist in organs such as ear and is often associated with mites (Cottew and Yeats, 1982; DaMassa, 1990).

Highly pathogenic CA caused by $M$. capricolum subsp. capricolum is widely distributed and, particularly in North Africa (Benkirane et al., 1993), but the frequency of occurrence is low (Bergonier et al., 1997). Such disease was observed in Australia, USA, Chile, Sweden and Oman (Nicolet, 1994). CA causes economic losses by decreased production, mortality, diagnosis and treatment costs; the losses can be high in severe outbreaks (Nicholas, 1998). The economic losses caused by CA was estimated to be $30 \$$ million in the European countries around the Mediterranean (Nicholas, 2002)
In Jordan, four small ruminant mycoplasmas ( $M$. mycoides subsp. mycoides LC, $M$. capricolum subsp. capricolum, $M$. putrfaciens, $M$. agalactiae) were isolated (Al-Momani et al., 2006). The prevalence of Mcc was not studied in Jordan. This study investigates the seroprevalence of $M$. capricolum subsp. capricolum among sheep and goat flocks in northern Jordan along with some risk factors associated with $M$. capricolum subsp. capricolum seropositivity.

\section{Materials and methods}

\section{Study area and animals:}

Jordan lies at the crossroad of three continents (Asia, Europe and Africa) and is considered a transit area for animal transportation from the northern to the southern states of the Middle East. There are six climatic zones in Jordan, including, the cool temperate rainy climate, warm temperate rainy climate, cool steppe climate, warm steppe climate, cool desert climate and warm desert climate (Anon, 1984). Jordan has 4 distinct seasons with an average temperature of $19^{\circ} \mathrm{C}$.

Small ruminants are the most abundant domestic animals in Jordan $74.3 \%$ are sheep and 23.2\% goats (Anon, 1995). Sheep and goats are usually kept together mainly under free range roaming transhumance husbandry with a small number of flocks adapting semi-intensive husbandry methods. Awassi sheep and local goats are the main small ruminant breeds in Jordan. The main sources of water used for sheep and goat drinking are collected rain, springs, dams and piped.

The routinely recommended control measure for infectious disease is vaccination. Currently, vaccines are used against; enterotoxaemia, brucellosis, pasteurellosis, anthrax, pox, foot and mouth disease and pest des petits ruminant, and no vaccine is used against $M$. capricolum subsp. capricolum.

The study area included the five Governorates (Irbid, Mafraq, Zarka, Ajloun and Jerash) of northern Jordan. The area coordinates are, $35^{\circ} 42 /$-38 $^{\circ} 12^{\prime}$ E, $32^{\circ} 17 /-32^{\circ} 34 / \mathrm{N}$ at $500-1200 \mathrm{~m}$ altitude above the sea level and the rainfall varied between 100 and $600 \mathrm{~mm}$. The temperature in winter varies between 4 and $8^{\circ} \mathrm{C}$ and $29-41^{\circ} \mathrm{C}$ in summer. The main small ruminant farming activities were within 3 climatic zones: the warm desert, cool temperate rainy, and the cool steppe. Flock's practice grazing during spring to early summer and in fall and winter supplements of fodders and concentrates were given. Lambing season lasts from November until May.

\section{Sample size determination and sampling:}

The prevalence of $M c c$ infections in northern Jordan was not reported previously, it was assumed 
to be $50 \%$. The total number of sheep and goat flocks in northern Jordan is estimated to be 10,000 (Anon, 2001). According to Thrusfield (1995) the appropriate number of flocks to be examined is 62 , because $95 \%$ level of confidence and $5 \%$ absolute precision were required. The main communal grazing areas were sampled. At least one flock/grazing area was included. Representative flock samples were selected according to estimated density in each area. The flocks were numbered in each grazing area, and then a number was drawn to be interviewed and sampled. On seven occasions farmers declined for different reasons; do not like blood to be drawn from their animals, the animal owner was not available to give the permission, absence of adult-male family members, and another number was drawn. A few flocks (39) from unshared grazing area (either private or common grazing area with no access to other farmers) were included. Thus, 104 flocks (18 sheep, 27 goat and 59 mixed) having 12093 sheep and 4225 goats were randomly selected. The maximum number of sheep/flocks is 620 and the minimum is 20 (Quartiles are $25 \%=40,50 \%=90,75 \%=200$ ). The maximum number of goat/flocks is 300 and the minimum is 8 (Quartiles are $25 \%=15,50 \%=25$, $75 \%=57$ ).

Due to limited fund, selection of individual sheep/goat for testing included the animal most likely to be infected in the flock (older or poorer condition). Thus, we sampled 5 to 10 female animals of $>2$ years of age/flock/species. All single species flocks were sampled, 20 mixed flocks were sampled from both species and 39 mixed species flocks were sampled from either sheep $(n=24)$ or goat $(n=15)$ depending on the main species in the flock.

During the months of 2002-2003, each farm flock was visited once for blood and data collection. Five milliliters blood samples were obtained from the jugular vein of each ewe $(n=678)$ in a vacuum tube without anticoagulant. Serum samples were separated and stored in aliquots at $-20^{\circ} \mathrm{C}$ until used.

\section{Data collection:}

A questionnaire was especially designed to collect information using closed questions. The collected information covered production and health management practices (see Table 1).

Table (1): Description of risk factors for flock-level small ruminant Mycoplasma capricolum subsp. capricolum seropositivity in northern Jordan

\begin{tabular}{|c|c|c|c|}
\hline \multirow[t]{2}{*}{ Variable } & \multirow[t]{2}{*}{ Coding } & \multicolumn{2}{|c|}{ Seropositivity to $M c c$} \\
\hline & & No $(n=57)$ & Yes $(n=47)$ \\
\hline \multicolumn{4}{|l|}{ A. Climatic zone } \\
\hline Warm steppe & 0 & 22 & 24 \\
\hline Hot desert & 1 & 17 & 11 \\
\hline Cold temperate & 2 & 18 & 12 \\
\hline \multicolumn{4}{|c|}{ B. Small ruminant species } \\
\hline Sheep & 0 & 9 & 9 \\
\hline Goat & 1 & 16 & 11 \\
\hline Mixed & 2 & 32 & 27 \\
\hline \multicolumn{4}{|c|}{ C. Source of animals, buying } \\
\hline \multicolumn{4}{|c|}{ No } \\
\hline \multirow[t]{2}{*}{ Yes } & 0 & 23 & 22 \\
\hline & 1 & 34 & 25 \\
\hline \multicolumn{4}{|l|}{ D. Drinking water } \\
\hline Rain & 0 & 1 & 2 \\
\hline Springa & 1 & 24 & 20 \\
\hline Pipes & 2 & 28 & 23 \\
\hline Mixed & 3 & 4 & 2 \\
\hline \multicolumn{4}{|c|}{ E1. Grazing locality } \\
\hline Same village & 0 & 43 & 36 \\
\hline Local area & 1 & 12 & 9 \\
\hline Others & 2 & 2 & 2 \\
\hline \multicolumn{4}{|c|}{ E2. Communal grazinga } \\
\hline No & 0 & 29 & 10 \\
\hline Yes & 1 & 28 & 37 \\
\hline \multicolumn{4}{|c|}{ E3. Grazing and concentrates } \\
\hline \multicolumn{4}{|c|}{ No } \\
\hline \multirow[t]{2}{*}{ Yes } & 0 & 39 & 34 \\
\hline & 1 & 18 & 13 \\
\hline \multicolumn{4}{|c|}{ F1. Introduce new SR into farm } \\
\hline \multicolumn{4}{|c|}{ No } \\
\hline \multirow[t]{2}{*}{ Yes } & 0 & 37 & 27 \\
\hline & 1 & 20 & 20 \\
\hline \multicolumn{4}{|c|}{ F2. Use outsider rams } \\
\hline No & 0 & 43 & 31 \\
\hline Yes & 1 & 14 & 16 \\
\hline \multicolumn{4}{|c|}{ F3. Sources of breeding animals } \\
\hline Same village & 0 & 42 & 36 \\
\hline Local area & 1 & 1 & 3 \\
\hline Other & 2 & 14 & 8 \\
\hline
\end{tabular}


Table 1 (Continued)

\begin{tabular}{|c|c|c|c|}
\hline \multirow[t]{2}{*}{ Variable } & \multirow[t]{2}{*}{ Coding } & \multicolumn{2}{|c|}{ Seropositivity to $M c c$} \\
\hline & & No $(n=57)$ & Yes $(n=47)$ \\
\hline \multirow{2}{*}{\multicolumn{4}{|c|}{$\begin{array}{l}\text { G1. Young separated from dam } \\
\text { No }\end{array}$}} \\
\hline & & & \\
\hline \multirow{2}{*}{ Yes } & 0 & 25 & 15 \\
\hline & 1 & 32 & 32 \\
\hline \multicolumn{4}{|c|}{ G2. Newborn barn with and without ewe } \\
\hline \multirow{2}{*}{ Yes } & 0 & 33 & 20 \\
\hline & 1 & 24 & 27 \\
\hline \multirow{2}{*}{\multicolumn{4}{|c|}{$\begin{array}{l}\text { H1. Weaning age, }<2 \text { months } \\
\text { No }\end{array}$}} \\
\hline & & & \\
\hline \multirow[t]{2}{*}{ Yes } & 0 & 45 & 44 \\
\hline & 1 & 12 & 3 \\
\hline \multicolumn{4}{|c|}{ H2. 2-6 months } \\
\hline No & 0 & 15 & 4 \\
\hline Yes & 1 & 42 & 43 \\
\hline \multicolumn{4}{|c|}{ I1. Udder cleaning } \\
\hline No & 0 & 38 & 32 \\
\hline Yes & 1 & 19 & 15 \\
\hline \multirow{2}{*}{\multicolumn{4}{|c|}{$\begin{array}{l}\text { I2. Change in milk production } \\
\text { No }\end{array}$}} \\
\hline & & & \\
\hline \multirow{2}{*}{ Yes } & 0 & 47 & 28 \\
\hline & 1 & 10 & 19 \\
\hline \multicolumn{4}{|c|}{ I3. Milking manual } \\
\hline No & 0 & 2 & 3 \\
\hline Yes & 1 & 55 & 44 \\
\hline \multicolumn{4}{|c|}{$\begin{array}{l}\text { I4. Cleaning milking utensils } \\
\text { No }\end{array}$} \\
\hline \multirow[t]{2}{*}{ Yes } & 0 & 40 & 27 \\
\hline & 1 & 17 & 20 \\
\hline \multicolumn{4}{|c|}{ J1. Neonatal death } \\
\hline No & 0 & 32 & 18 \\
\hline Yes & 1 & 25 & 29 \\
\hline \multicolumn{4}{|c|}{ J2. Neonatal death/year } \\
\hline No death & 0 & 23 & 16 \\
\hline$<5$ & 1 & 15 & 17 \\
\hline $5-10$ & 2 & 9 & 11 \\
\hline$>10$ & 3 & 10 & 3 \\
\hline \multicolumn{4}{|c|}{ K1. Treat against parasite } \\
\hline No & 0 & 19 & 9 \\
\hline Yes & 1 & 38 & 38 \\
\hline
\end{tabular}

Table 1 (Continued)

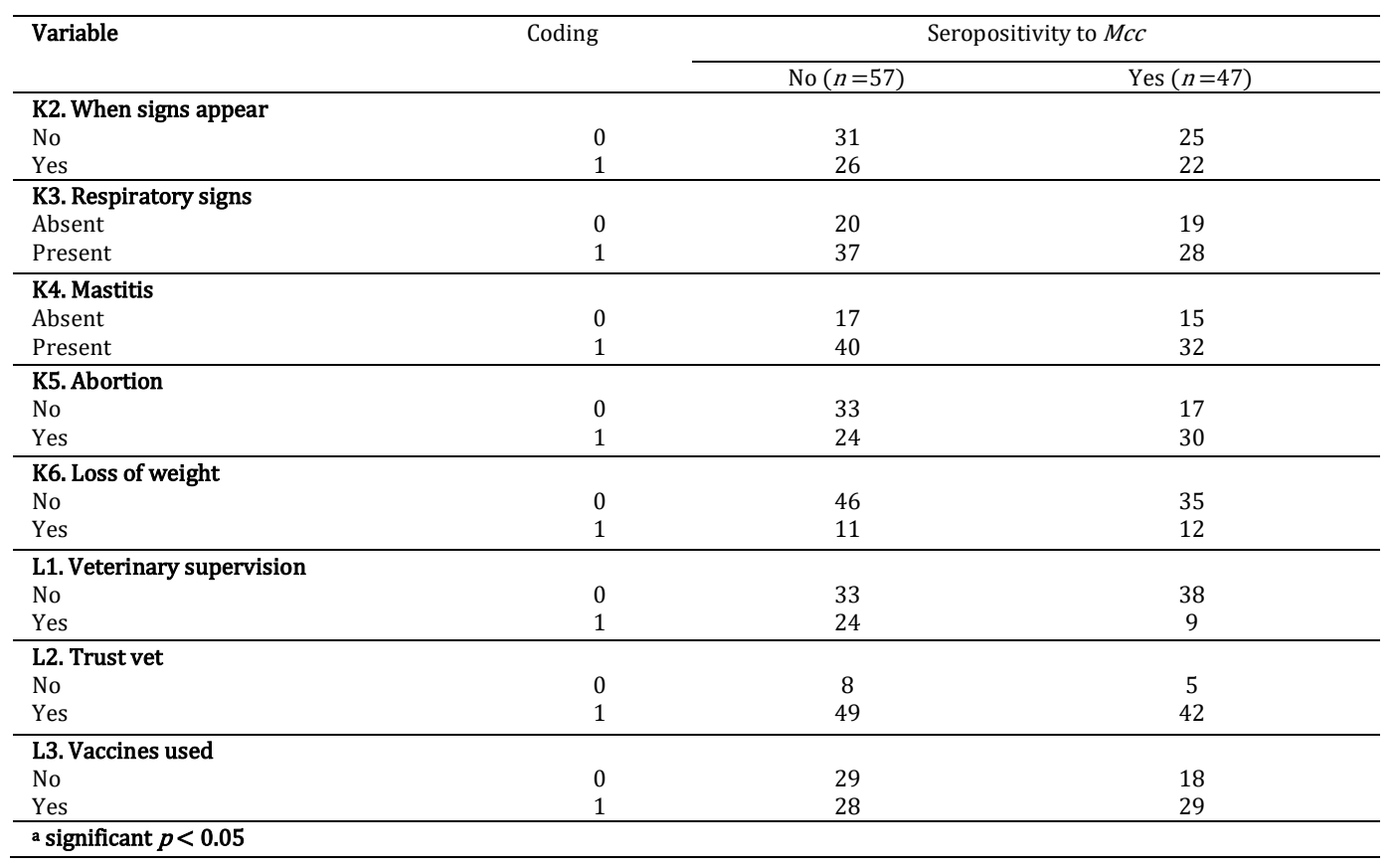


The questionnaire was filled by direct interview with the farmers and conducted by a veterinarian who spoke the same dialect of Arabic as the farmers, so there was no problem in communication.

\section{ELISA}

The iELISA was adapted from Nicholas et al. (1996) for the detection of antibodies against $M$. agalactiae in small ruminant sera.

M. capricolum subsp. capricolum antigen was diluted in carbonate-bicarbonate buffer $\mathrm{pH} 9.6$ $\left(\mathrm{Na}_{2} \mathrm{CO}_{3} ; \mathrm{NaHCO}_{3}\right) 1 / 400$ and coated on Nunk Maxi Sorp microtiter plates with $100 \mu \mathrm{l}$ in each well. The plates were incubated overnight at $4{ }^{\circ} \mathrm{C}$, and then washed 4 times with PBST pH 7.4 to remove the unabsorbed antigens. To the washed wells 100 $\mu \mathrm{l} /$ well of the serum (1/100 dilution) were added. The plates were incubated at $37^{\circ} \mathrm{C}$ for 30 minutes and then washed 4 times with PBST. Then $100 \mu$ of donkey anti-sheep IgG conjugated to alkaline phosphatase (Sigma) diluted 1/ 12000 in PBS with Marvel and Tween 20 was added to each well and incubated at $37^{\circ} \mathrm{C}$ for 30 minutes; then the wells were washed 4 times with PBST. The colour was developed after incubation with $100 \mu$ l of 5-Bromo4-chloro-3-Indolyl Phosphate/ Nitro Blue Tetrazolium (BCIP/ NBT) alkaline phosphatase substrate and the color development was stopped by the addition of $50 \mu \mathrm{l}$ of $1 \mathrm{M}$ citric acid. The absorbance was determined at $405 \mathrm{~nm}$ by BIO-TEK INSTRUMENTS, ELX 800 ELISA plate reader. This test sensitivity and specificity are $82 \%$ and $97 \%$ respectively. A positive and negative control samples were tested in this sheep and goat ELISA system. A flock was considered seropositive when one or more samples were positive. The cutt-off value was calculated as the mean $\mathrm{OD}_{405}$ value of the negative controls.

Statistical methods:
The true seroprevalence (Rogan and Gladen, 1978) and 95\% confidence intervals were calculated for seroprevalences. Chi-square analysis was employed to test the significance between prevalences. $P$ value of $<0.05$ was considered significant. Odds ratio and its 95\% confidence intervals were calculated. SPSS 11 program was used (Anon. 2001).

Data were analyzed according to the casecontrol design, where $M$. capricolum subsp. capricolum seropositive and seronegative flocks were compared in relation to exposure to potential risk factors (Thrusfield, 1995). Variables that were associated with $M$. capricolum subsp. capricolum sero-positive flocks at $p<0.25$ were used in multivariable logistic regression (Hosmer and Lemeshow, 1989). It was checked whether these variables showed a correlation of more than 0.05 with each other.

In the multivariable model, variables were excluded from the model by forward procedure. The least-significant variables (based on Wald's statistic) were deleted, the model fitted, and the results then compared (both parameters estimate and difference in -2log likelihood of the model) with those of the previous run to check for confounding with a change in parameter estimates of more than $30 \%$, the deleted variable was a confounder and included in the model again. This resulted in a model containing variables related to $M$. capricolum subsp. capricolum seropositivity $(p<0.05)$. Two-way interaction was tested for significance.

\section{Results}

\section{Seroprevalences:}

Seroprevalences of $M$. capricolum subsp. capricolum were calculated and analyzed as flocklevel seroprevalence for small ruminants (both sheep and goats); sheep and goat (Table 2).

Table (2): Seroprevalence of Mycoplasma capricolum subsp. capricolum in small ruminant flocks by iELISA during January 2002 to December 2003, in northern Jordan

\begin{tabular}{|c|c|c|c|c|c|c|c|c|}
\hline \multirow[t]{2}{*}{ Species } & \multicolumn{4}{|c|}{ Flock-level } & \multicolumn{4}{|c|}{ Individual-level } \\
\hline & $\begin{array}{c}\text { No. } \\
\text { examined }\end{array}$ & Prevalence & $\begin{array}{c}\text { True } \\
\text { seroprevalence }\end{array}$ & $95 \% \mathrm{CI}$ & $\begin{array}{c}\text { No. } \\
\text { examined }\end{array}$ & Prevalence & $\begin{array}{c}\text { True } \\
\text { seroprevalence }\end{array}$ & $95 \% \mathrm{CI}$ \\
\hline $\begin{array}{c}\text { Small } \\
\text { ruminant }\end{array}$ & 104 & $47 \%$ & $56 \%$ & 36,55 & 678 & $17 \%$ & $18 \%$ & 15,20 \\
\hline Sheep & 62 & $34 \%$ & $39 \%$ & 29,53 & 376 & $17 \%$ & $18 \%$ & 14,22 \\
\hline Goat & 62 & $25 \%$ & $28 \%$ & 43,67 & 302 & $17 \%$ & $18 \%$ & 13,22 \\
\hline
\end{tabular}


The flock level seroprevalence of $M$. capricolum subsp. capricolum were 56\%, 39\%, 28\% in small ruminants (sheep and goats) sheep and goats respectively. There was no significant difference $\left(X^{2}\right.$ $=2$, d.f. $=1, p=0.15$ ) at the flock level seroprevalences of sheep and goats.

\section{Multivariable analysis:}

Out of twenty-nine variables six variables were associated at $P<0.25$ with $M$. capricolum subsp. capricolum seropositivity. After forward selection (Table 1), only two variables remained in the final logistic regression model, namely, communal grazing and drinking water, spring (Table 3).

Table (3): Logestic regression analysis of factors associated with seropositivity to Mycoplasma capricolum subsp. capricolum in small ruminant's flocks in Jordan

\begin{tabular}{|c|c|c|c|c|c|}
\hline Risk factors & $\beta$ & $\begin{array}{l}E \\
\text { 3) }\end{array}$ & $P$ & $O R$ & $95 \% \mathrm{CI}$ \\
\hline Communal grazing & 0.224 & 0.14 & 0.001 & 5.2 & 2,13 \\
\hline Drinking water, spring & 0.224 & 0.078 & 0.004 & 0.27 & $0.1,0.66$ \\
\hline Constant & 0.136 & 0.476 & 0.11 & NA & NA \\
\hline
\end{tabular}

Likelihood ratio of chi-square (LR $x 2$ ): -62 on 2 degrees of freedom.

\section{Discussion}

The results showed a high flock-level true seroprevalence of $56 \%$ among small ruminant flocks in northern Jordan which can be explained by the local herding practices and transhumance, the movement of animals from eastern Jordan to the west during spring and early summer seeking better pasture, cross-border movements with the neighboring Arab countries namely Syria, Iraq and Saudi Arabia, which can easily transmit the disease across boundries. There was no study of small ruminants seroprevalence of $M$. capricolum subsp. capricolum either on flock or individual levels.

The seroprevalence of $M$. capricolum subsp. capricolum in Jordan was never studied before. Mcc is widely distributed and highly pathogenic, particularly in North Africa (Benkirane et al., 1993), but the frequency of occurrence is low (Bergonier et al., 1997). Such a disease was observed in Australia, USA, Chile, Sweden, and Oman (Nicolet, 1994). In Jordan, small ruminants had lower true seroprevalences of both $M$. agalactiae (30\%) (AlMomani et al., 2008) and M. mycoides subsp. capri (36\%) (Al-Momani et al., 2010) compared to the true seroprevalence results of $M$. capricolum subsp. capricolum in this study.

Goats are more commonly affected than sheep, and clinical signs of fever, septicaemia, mastitis, and severe arthritis may be followed rapidly by death (Bolske et al., 1988). In this study we found that both species are equally susceptible to $M$. capricolum subsp. capricolum. In Jordan many small ruminant flocks (93\%) are mixed flocks (Abo-Shehada et al., 2002) and this may reflect as equal exposure to the infection of $M$. capricolum subsp. capricolum in these mixed flocks. Infected mixed flocks will facilitate equal exposure pressure on both sheep and goats and subsequent transmission of $M$. capricolum subsp. capricolum.

In this study, out of twenty-nine health management and production variables only two, namely, the use of communal grazing was found as risk factor for $M$. capricolum subsp. capricolum seropositivity and using spring water for animals drinking was found as a protective risk factor for $M$. capricolum subsp. capricolum seropositivity.

Using communal grazing by different flocks $(\mathrm{OR}=5.2,95 \%$ CI: 2, 13) increased the risk for $M$. capricolum subsp. capricolum seropositivity. Such practice will contaminate pasture with all pathogens carried by any of the grazing animals. Subsequently, the pathogen will be picked up by susceptible animals that get infected and increase the number of seropositive animals in all flocks frequent the communal pasture.

Using spring water for drinking $(\mathrm{OR}=0.27,95 \%$ CI: $0.11,0.66)$ was protective risk factor leading to decrease seropositive animals in the flock. This indicates that the other sources of drinking water (rain, pipes, mixed) may be exposed to contaminants leading to increase the seropositivity of $M$. capricolum subsp. capricolum in these flocks.

The education of farmers regarding the use of communal grazing and water sources is expected to help reducing the $M$. capricolum subsp. capricolum infections in their flocks.

Acknowledgements: We thank the Karim Rida Said Foundation for their financial support.

\section{References}

1. Abo-Shehada, M.N., Arab, B., Mukbel, R., Williams, D. \& Torgerson, P.R., (2002). Age and seasonal variations in the prevalence of Oestrus ovis larvae among sheep in northern Jordan. Preventive Veterinary Medicine, 47(3): 205-212, https://doi.org/10.1016/s0167-5877(00)00160-4.

2. Al-Momani, W., Halablab, M.A., Abo-Shehada, M.N., Miles, K., McAuliffe, L. Nicholas, \& R.A.J. (2006). Isolation and characterization of small ruminant mycoplasmas in Jordan using denaturing gradient gel electrophoresis (DGGE) and specific PCR. Small Ruminant Research, 65:106-112 
3. Al-Momani, W., Nicholas, R.A.J. \& Abo-Shehada, M.N., (2008). Seroprevalence of and risk factors for Mycoplasma agalactiae among small ruminants in northern Jordan. Preventive Veterinary Medicine, 83(1): 1-10, https://doi.org/10.1016/j.prevetmed.2007.08.003.

4. Al-Momani, W., Nicholas, R.A.J. \& Abo-Shehada, M.N., (2010). Sero-prevalence and risk factors of Mycoplasma mycoides subsp. capri LC among small ruminants in northern Jordan. Tropical Animal Health and Production, In Press

5. Anonymous. (1984). National Atlas of Jordan. Climate and Agroclimatology. Jordan National Geographic Center, pp. 135

6. Anonymous., (1995). The Annual Report. Ministry of Agriculture, Jordan

7. Anonymous., 2001. The Annual Report. Ministry of Agriculture, Jordan

8. Bashiruddin, J.B., Taylor, T.K. \& Gould, A.R., (1994). A PCR based test for the specific identification of Mycoplasma mycoides subsp. mycoides SC. Journal of Veterinary Diagnostic Investigation, 6: 428-434

9. Benkirane, A., Amghar, S. \& Kirchhoff, H., (1993). Analysis of membrane proteins of Mycoplasma capricolum strains by SDS-PAGE and immunoblotting. Journal of Veterinary Medicine, 40(1-10): 119-124, https://doi.org/10.1111/j.14390450.1993.tb00118.x.

10. Bergonier, D., Bertholet, X. \& Poumarat, F., (1997). Contagious agalactia of small ruminants: current knowledge concerning epidemiology, diagnosis, and control. Revue Scientifique et Technique- Office International des Epizooties, 16(3): 848-873, https://doi.org/10.20506/rst.16.3.1062.

11. Bolske, G., Msami, H., Humleslo, N.E., Erno, H. \& Jonsson, L., (1988). Mycoplasma capricolum in an outbreak of polyarthritis and pneumonia in goats. Acta Veterinaria Scandinavia, 29(3-4): 331-338, https://doi.org/10.1186/bf03548626.

12. Bolske, G., (1995). Respiratory mycoplasmoses in goats: Especially regarding contagious caprine pleurpneumonia. Department of Veterinary Microbiology, Swedish university of Agricultural Sciences. Ph.D thesis Uppsala, Sweden

13. Cottew, G.S. \& Yeats, F.R., (1982). Mycoplasma and mites in the ears of clinically normal goats. Australian Veterinary Journal, 59(3): 77-81, https://doi.org/10.1111/j.1751-0813.1982.tb02731.x.

14. DaMassa, A.J., (1990). The ear canal as a culture site for demonstration of mycoplasmas in clinically normal goats. Australian Veterinary Journal, 67(7): 267-269, 0813.1990.tb07786.x. https://doi.org/10.1111/j.1751-

15. DaMassa, A.J., Wakenell, P.S. \& Brooks, D.L, (1992). Mycoplasmas of goats and sheep. Review Article.
Journal of Veterinary Diagnostic Investigation, 4(1): 101-113, https://doi.org/10.1177/104063879200400126.

16. Hosmer, D. \& Lemeshow, S. (1989). Applied logistic regression. Wiley, New York, pp 307.

17. Nicholas, R.A.J., Santini, F.G., Clark, K.M., palmer, N.M.A., De Santis, P. \& Bashiruddin, J.B. (1996). A comparison of serological tests and gross lung pathology for detecting contagious bovine pleuropneumonia in two groups of Italian cattle. Veterinary Record, 139(4): 89-93, https://doi.org/10.1136/vr.139.4.89.

18. Nicholas, R.A.J. (1998). Mycoplasmas of small ruminants and their relevance to Macedonia. Proceeding of the meeting (6 $6^{\text {th }}$ International conference on sheep and Goat Production and $4^{\text {th }}$ symposium on the reproduction of domestic animals), Ohrid, Macedonia.

19. Nicholas, R.A.J. (2002). Improvements in the diagnosis and control of diseases of small ruminants caused by mycoplasmas. Small Ruminant Research, 45(2): 145-149, https://doi.org/10.1016/s09214488(02)00095-0.

20. Nicolet J. (1994). Mycoplasma infections in cattle, sheep, and goats: Methods for diagnosis and prophylaxis. Office International des Epizooties

21. Perreau, P. \& Breard, A. (1979). La mycoplasmose caprine a M. capricolum. Comparative Immunology Microbiology and Infectious Diseases, 2(1): 87-97, https://doi.org/10.1016/0147-9571(79)90062-6.

22. Poveda, J.B. \& Nicholas, R.A.J. (1998). Serological identification by growth inhibition and metabolic inhibition tests. In: Miles R.J and Nicholas R.A.J. Eds. Mycoplasma Protocols. Totawa, USA: Humana Press, pp.105-113.

23. Rodriguez, J.L., Gutierrez, C., Brooks, D.L., Damassa, A.J., Oros, J. \& Fernandez, A., (1998). A pathological and immunohistochemical study of goat kids undergoing septicemic disease caused by Mycoplasma capricolum subsp. capricolum, Mycoplasma capri and Mycoplasma mycoides subsp. mycoides LC. Journal of Veterinary Medicine, 45(110): 141-149, https://doi.org/10.1111/j.14390450.1998.tb00777.x.

24. Rogan, W.J. \& Gladen, B. (1978). Estimating prevalence from the results of a screening test. American Journal Epidemiology, 107(1): 71-76, https://doi.org/10.1093/oxfordjournal s.aje.a112510.

25. Ruffin, D.C., (2001). Mycoplasma infections in small ruminants. Veterinary Clinical of North America for Food and Animal Practice Review, 17(2): 315-332, https://doi.org/10.1016/s0749-0720(15)30031-1.

26. Thrusfield, M., (1995). Veterinary Epidemiology. Blackwell Science, London, p. 182. 